\title{
Música e Neurodesenvolvimento: em busca de uma poética musical inclusiva
}

Music and neurodevelopment: searching for an inclusive music poetic

$\underline{\underline{\text { Mauro Muszkat }}}$

1 Médico neurologista, músico e compositor. Tem mestrado, doutorado e pós em neurociências pela UNIFESP. Atua como coordenador do Núcleo de Atendimento Neuropsicológico Interdisciplinar Infantil (NANI) do Departamento de Psicobiologia da UNIFESP. Professor no Programa de Educação e Saúde da Infância e Adolescência (UNIFESP). Lidera o Grupo de Pesquisa em Reabilitação e Ensino em Neurociência Educacional do CNPq. 
O ensaio que se segue versa sobre a contribuição da Neurologia para o desenvolvimento na Educação Musical. Há centenas de estudiosos, em grupos de pesquisa e instituições, que pesquisam a relação entre neurodesenvolvimento e música, em várias situações, por exemplo, na depressão ou Alzheimer. Conjugar um tipo de música (cantigas, canções folclóricas, brincadeiras, canções mais primitivas do repertório cultural da criança, peças instrumentais), que tipo de audição ou processo musical, ou de diálogo musical pode facilitar o tratamento de pessoas com depressão catatônica, de crianças com transtornos de espectro autista, com lesões cerebrais, com paralisia cerebral, bem como ativar as redes motivacionais da criança ou adolescente vulnerável em razão desses transtornos e também em razão de desfavorecimento socioeconômico. Pretende-se, com este ensaio, chamar a atenção de arte-educadores, músicos e educadores para a confluência dessas duas áreas do conhecimento, com o intuito de que a leitura os ajude a pensar os aspectos técnicos em conjunto com os subjetivos quando se propõe a observar a criança elou a intervir junto a ela no processo de construção de linguagem, de maneira a encontrar respostas para as dificuldades e para a inclusão dessa criança, seja pedagógica ou social. O compromisso de preparar cérebros conscientes e ativos para que os jovens tenham condições de enfrentar os desafios para a solução das questões complexas do nosso mundo está inexoravelmente ligado a um trabalho que proponha sentimentos compartilhados e convergentes a partir de uma experiência emocional, estética e artística.

A música em qualquer uma de suas dimensões, enquanto estética, terapia ou ritual, envolve as funções cerebrais perceptivo-motoras e executivas (13). Sentir e processar música implica a análise de sinais físicos e acústicos das vibrações de moléculas do ar (sons) e decodificação em um sistema subjetivo e cultural complexo. Assim, sinais físicos transformam-se em estados emocionais que refletem expectativas, tensão, repouso e movimento, bem como causam flutuações de nossos ritmos fisiológicos endógenos, como batimento cardíaco, frequência respiratória e ritmos elétricos cerebrais $(1,2,13,14)$.

O processamento musical envolve uma ampla gama de áreas cerebrais relacionadas à percepção de alturas, timbres, ritmos, à decodificação métrica, melódico-harmônica, e à gestualidade implícita e modulação do sistema de prazer e recompensa que acompanham nossas reações psíquicas e corporais à música $(2,5,7)$ Enquanto ouvimos ou executamos música, o cérebro sincroniza durações, agrupa e cria distinções entre sons e timbres, reconhece consonâncias e dissonâncias, programa movimentos precisos na execução instrumental e leitura, 
e armazena e evoca melodias familiares e ritmos. Ao compreendermos como tais processos modulares integram percepções múltiplas em uma experiência singular, essencialmente emocional, que seduz e direciona nossos sentidos, nosso corpo e cognição, podemos elucidar aspectos fundamentais da mente humana, da emergência da consciência a partir da emoção, e da percepção implícita à consciência autorreflexiva $(3,14,16)$. Se, por um lado, a neurociência tradicionalmente lida com a objetividade dos dados e com os sinais que mapeiam o funcionamento cerebral, por outro, a música não pode ser entendida sem levarmos em conta a subjetividade, o envolvimento lúdico e a transitividade que caracterizam a arte.

\section{Neurobiologia da Música}

A atividade musical mobiliza amplas áreas cerebrais, tanto as filogeneticamente mais novas (neocórtex) como os sistemas mais antigos e primitivos, como o chamado cérebro reptiliano, que envolve o cerebelo, as áreas do tronco cerebral e a amígdala cerebral $(2,7,13)$. As vibrações sonoras, resultantes do deslocamento de moléculas de ar, provocam distintos movimentos nas células ciliares (receptoras) localizadas no ouvido interno e são transmitidas para centros do tronco cerebral. A frequência de vibração dos sons tem uma correspondência com a localização das células ciliadas do ouvido interno e a intensidade dos sons está diretamente relacionada ao número de fibras que entram em ação. Quanto mais intenso o som, mais fibras entram em ação. Existe uma relação entre a localização da célula sensorial na cóclea e a frequência de vibração dos sons. A frequência que mais excita uma célula sensorial muda sistematicamente de alta (sons agudos) para baixa frequência (sons graves). Assim, os estímulos sonoros nas chamadas células ciliares são levados pelo nervo auditivo de maneira organizada ao córtex auditivo (lobo temporal). O primeiro estágio, a senso-percepção musical, se dá nas áreas de projeção localizadas no lobo temporal no chamado córtex auditivo, ou área auditiva primária, responsável pela decodificação da altura, do timbre, do contorno e do ritmo $(1,2,7,13)$. Tal área conecta-se com o restante do cérebro em circuitos de ida e volta, e com áreas da memória como o hipocampo, que reconhece a familiaridade dos elementos temáticos e rítmicos, bem como com as áreas de regulação motora e emocional, como o cerebelo 
e a amígdala (que atribuem um valor emocional à experiência sonora), e um pequeno núcleo de substância cinzenta (núcleo accumbens) relacionado ao sentido de prazer e recompensa $(1,2,7,13)$. Enquanto as áreas temporais do cérebro são aquelas que recebem e processam os sons, algumas áreas específicas do lobo frontal são responsáveis pela decodificação da estrutura e da ordem temporal dos sons, isto é, pelo comportamento musical planejado. Há uma especialização hemisférica para a música, no sentido do predomínio do lado direito para a discriminação da direção das alturas (contorno melódico), do conteúdo emocional da música e dos timbres (nas áreas temporais e frontais), enquanto que o ritmo, a duração e a métrica, e a discriminação da tonalidade se dão predominantemente no lado esquerdo do cérebro. $\mathrm{O}$ hemisfério cerebral esquerdo também analisa os parâmetros de ritmo e altura, interagindo diretamente com as áreas da linguagem, que identificam a sintaxe musical $(1,2,13)$.

A música não apenas é processada no cérebro, mas afeta seu funcionamento. As alterações fisiológicas com a exposição à música são múltiplas e vão desde a modulação neurovegetativa dos padrões de variabilidade dos ritmos endógenos da frequência cardíaca, dos ritmos respiratórios, dos ritmos elétricos cerebrais, dos ciclos circadianos de sono-vigília, até a produção de vários neurotransmissores ligados à recompensa e ao prazer e ao sistema de neuromodulação da dor $(2,5,7,14)$.

\section{Música e Plasticidade Cerebral}

Treinamento musical e exposição prolongada à música considerada prazerosa aumentam a produção de neurotrofinas produzidas em nosso cérebro em situações de desafio, podendo determinar não só o aumento da sobrevivência de neurônios, como as mudanças de padrões de conectividade na chamada plasticidade cerebral $(2,13,14,16)$.

A experiência musical modifica estruturalmente o cérebro. Pessoas sem treino musical processam melodias preferencialmente no hemisfério cerebral direito, enquanto, nos músicos, há uma transferência para o hemisfério cerebral esquerdo. O treino musical também aumenta o tamanho e a conectividade (maior número de sinapses-contatos entre os neurônios) de várias áreas cerebrais, como o corpo caloso (que une um lado a outro do cérebro), o cerebelo 
e o córtex motor (envolvido com a execução de instrumentos). A ativação maior de áreas do hemisfério cerebral esquerdo pode potencializar não só as funções musicais, mas também as funções linguísticas, que são sediadas neste mesmo lado do cérebro. Vários circuitos neuronais são ativados pela música, uma vez que o aprendizado musical requer habilidades multimodais que envolvem a percepção de estímulos simultâneos e a integração de várias funções cognitivas, como a atenção e a memória, e das áreas de associação sensorial e corporal, envolvidas tanto na linguagem corporal quanto simbólica $(2,7,8,13,17)$. As crianças, de maneira geral, expressam as emoções mais facilmente pela música do que pelas palavras. Neste sentido, o estudo da música pode ser uma ferramenta única para a ampliação do desenvolvimento cognitivo e emocional das crianças, incluindo aquelas com transtornos ou disfunções do neurodesenvolvimento, como o déficit de atenção e a dislexia. A música, principalmente com conteúdo familiar, facilita a conectividade de experiências emocionalmente carregadas, e pode ter um valor potencial na abordagem de pessoas que têm transtornos neuropsiquiátricos como autismo, depressão, esquizofrenia $(13,15,18,19,20)$.

Em pessoas com declínio cognitivo, a música pode facilitar a ativação de redes neurais altamente plásticas, e envolvidas com memórias autobiográficas episódicas em indivíduos com disfunções cerebrais. Assim, o benefício da música nas demências já é amplamente reconhecido por vários grupos internacionais, dada a capacidade da música de evocar emoções e trazer memórias ocultas. É reconhecido também o fato de a aptidão musical e a apreciação serem habilidades que permanecem intactas ou muitas vezes tardiamente afetadas em diversos indivíduos com demência. A música pode, também, facilitar a intimidade e a aproximação física dos indivíduos com seus cuidadores, com maior engajamento em tarefas e melhor modulação positiva do humor. $(6,11,12,13)$

\section{Estimulando o Cérebro Musical}

O uso da música para fins terapêuticos data de tempos ancestrais e apoia-se na capacidade musical de evocar e estimular uma série de reações fisiológicas que fazem a ligação direta entre o cérebro emocional e o cérebro executivo. A música estimula a flexibilidade mental e a 
coesão social, fortalecendo vínculos e o compartilhamento de emoções que nos fazem perceber que o outro é parte do nosso sistema de referência. $(5,6,7)$. Vários estudos revelam efeitos clínicos da música na precisão dos movimentos da marcha e no controle postural, facilitando a expressão de estados afetivos e comportamentais em indivíduos com depressão e ansiedade. Tais efeitos positivos da música têm sido observados em transtornos do desenvolvimento como o déficit de atenção e a dislexia, bem como na doença de Parkinson, na doença de Alzheimer ou em doentes com espasticidade, nos quais a reabilitação com música ou com estímulos a ela relacionados, como dança, ritmos ou jogos musicais, potencializa as técnicas de restabelecimento físico e cognitivo $(6,11,13)$.

\section{Música, Cognição e Neurodesenvolvimento}

A inteligência musical é um traço compartilhado e mutável que pode estar presente em grau até acentuado, mesmo em crianças com deficiência intelectual. O período do neurodesenvolvimento mais sensível para o aperfeiçoamento de habilidades musicais se dá nos primeiros oito anos de vida $(1,5,8)$. Estudos com potenciais evocados mostram que bebês, já nos primeiros três meses de vida, apresentam várias competências musicais para reconhecer o contorno melódico, diferenciam consonâncias e dissonâncias e também mudanças rítmicas. A exposição precoce à música, além de facilitar a emergência de talentos ocultos, contribui para a construção de um cérebro biologicamente mais conectado, fluido, emocionalmente competente e criativo. Crianças em ambientes sensorialmente enriquecedores apresentam respostas fisiológicas mais amplas, maior atividade das áreas associativas cerebrais, maior grau de neurogênese (formação de novos neurônios em área importante para a memória como o hipocampo) e diminuição da perda neuronal (apoptose funcional). A educação musical favorece a ativação dos chamados neurônios em espelho, localizados em áreas frontais e parietais do cérebro, e essenciais para a chamada cognição social humana, um conjunto de processos cognitivos e emocionais responsáveis pelas funções de empatia, ressonância afetiva e compreensão de ambiguidades na linguagem verbal e não verbal $(5,7,8,15)$.

Em relação à música no neurodesenvolvimento, também é conhecido o fato de ela 
influenciar positivamente o desenvolvimento infantil, uma vez que, enquanto a criança ouve e toca um instrumento, ela opera com forças culturais de ação, exercita a fala egocêntrica e desenvolve autocontrole e regras. A música também fortalece o sistema de cognição social, uma vez que facilita as representações internas e o reconhecimento de emoções e empatia. Além disso, pode facilitar a atenção compartilhada, uma vez que a atividade musical sempre envolve mediação humana e ocasionalmente com pares, facilitando trocas inter-geracionais $(14,17,18)$.

O período da adolescência implica transição, com mudanças não apenas hormonais, mas neurobiológicas, como o aumento da substância branca, a diminuição da substância cinzenta neocortical e a perda de $1 / 3$ de neurônios dopaminérgicos. Tais mudanças coincidem com observações comportamentais de maior impulsividade, agilidade motora e períodos de humor oscilante e de tédio. A música na adolescência, neste sentido, pode facilitar respostas emocionais positivas, diminuindo o período de oscilação de humor e aumentando o engajamento em atividades de grupo e o compartilhamento de tarefas. Adolescentes multi-tarefas da era digital fazem atividades simultâneas (mandam e-mails, mensagens de WhatsApp, ouvem músicas e veem vídeos), o que super-estimula o cérebro automático, mas os priva de experiências relacionais, no sentido de participação pouco ativa na resolução de problemas mais complexos que envolvem vínculo afetivo e empatia $(7,17)$.

Em um trabalho do grupo de Nina Kraus em Chicago (17), adolescentes foram subdivididos em dois grupos de treinamento durante um período de três anos, no qual 19 foram sujeitos ao ensino musical em uma frequência de três horas semanais que consistia de técnica instrumental, estudo de instrumento, teoria musical e desempenho orquestral; enquanto que o grupo de 21 adolescentes foi submetido a um treino (com oficiais de reserva) relacionado a exercícios físicos, incluindo marcha sincronizada e desempenho em competições esportivas com a mesma frequência. Após avaliação extensiva pré e pós-treino o grupo de ensino musical teve desempenho superior ao grupo de oficiais de reserva nas tarefas de linguagem, nomeação rápida, interpretação de texto, com mudanças também mensuráveis nos potenciais evocados cognitivos, em que houve mudanças na amplitude e na latência dos potenciais apenas no grupo com estímulo musical. Vários estudos avaliam as propriedades neuropsicológicas positivas do estudo musical sobre o neurodesenvolvimento, pré-ativando habilidades espaciais, melhorando autorregulação emocional, facilitando tarefas de estimativa temporal como na matemática, 
e que tais atividades modificam-se permanentemente, alterando de maneira positiva o comportamento das crianças $(5,8,13)$.

No que se refere aos transtornos do neurodesenvolvimento, tem sido relatado que, em crianças com transtorno do Espectro Autista (TEA), a audição musical e a terapia com música minimizam rituais motores, facilitam a atenção seletiva e o comportamento exploratório motivado pelos efeitos positivos de ativação de áreas do sistema de recompensa, e modulam regiões pré motoras $(2,5)$.

No Transtorno do Déficit de Atenção/Hiperatividade (TDAH), são descritas a redução da impulsividade e a melhora da auto monitorização de tarefas motoras, principalmente nas crianças com disfunções executivas $(1,3)$. Em pessoas com epilepsia, a audição de determinadas músicas pode diminuir a frequência de descargas epileptiformes, tanto durante a vigília quanto durante o sono (4).

Em crianças com transtorno da aprendizagem da leitura/escrita, a audição musical pode pré-ativar áreas associativas de linguagem, como a área de Broca, o que potencialmente facilitaria o processamento fonológico. Neste sentido, a música facilita um processo de neurodesenvolvimento saudável, pois faz com que a mente torne-se ativa pela excitação do sistema de autorreferência e de memórias auto-biográficas, e faz com que o corpo mantenha-se dinâmico pelo movimento na execução musical ou nas respostas corporais ao som ou à dança, integrando-se emoção a ação $(1,5,6,16)$. O avanço das correlações da música com a função cerebral exige, cada vez mais, um trabalho multidisciplinar (realizado entre músicos, neurologistas e educadores musicais) que dê acesso à multiplicidade de experiências musicais, lúdicas, criativas, prazerosas, na análise do impacto da música no neurodesenvolvimento. Trazer a extensão dos avanços tecnológicos integrados à música, a mais emocional das artes, pode também facilitar o nosso poder de discernimento e consciência, tanto das nossas potencialidades, como de vulnerabilidades, enquanto seres emocionais.

Citando o neurobiológico Henrique Maturana: "Não é certo que nós, seres humanos, somos seres racionais por excelência. Somos, como mamíferos, seres emocionais que usam a razão para justificar e ocultar as emoções que dão bases para as nossas ações.” 


\section{Referências}

Andrade,, P.E. Uma abordagem evolucionária e neurocientífica da música. Neurociências. 1 (1): 21-33, 2004.

Blood A. J., Zatorre R. J., Bermudez P., et al. (1999) Emotional responses to pleasant and unpleasant music correlate with activity in paralimbic brain regions. Nature Neuroscience, $2,382-387$.

Carrer, L.R.J (2015) Music and sound in time processing of children with ADHD. Front Psych 6:127. doi:103389/fpsyt:2015.00127

Bodner M., Turner R. P., Schwacke J., et al. (2012) Reduction of seizure occurrence from exposures to auditory stimulation in individuals with neurological handicaps: a randomized controlled trial. PLoS One, 7, e45303.

Dumont, E.; Syurina, E.V., Feron, F.J.M., van Hooren, S (2017) Music Intervention and Child Development; a Critical Review and Further Directions, Front Psychol,8: 1694 doi 10.3389/ fpsyg.2017.01694

Hegde, S. (2017) Music Therapy for Mental Disorder and Mental health; The untapped potential of Indian Classical Music BJPsychic International 2(14), may.

Levitin, D. A Música no seu cérebro: a ciência de uma obsessão humana. Rio de Janeiro: Civilização Brasileira, 2010.

Jaschke, A.C.; Honing,H.; Scherder, E.J.A (2018) Longitudinal Analysis of Muisc Education on Executive Functions in Primary School Children. Frontiers in Neurosciece, 23; DOI $10.3389 /$ fnins.2018.00103 
Langer S. K. (1951) Philosophy in a New Key. Harvard University Press.

Maratos A. S., Gold C., Wang X., et al. (2008) Music therapy for depression. Cochrane Database of Systematic Reviews, (1), CD004517. [

Mithen S. (2005) The Singing Neanderthals. Weidenfeld and Nicholson.

Mula M. \& Trimble M. R. (2009) Music and madness: neuropsychiatric aspects of music. Clinical Medicine, 9, 83-86.

Muszkat, M; Correia, CMF; Campos, SM (2000). Música e Neurociências. In: Revista de Neurociências.; 8 (2): 70-75

Sloboda, J. A mente musical: a psicologia cognitiva da música. Tradução Beatriz Ilari e Rodolfo Ilari. Londrina: EDUEL, 2008.

Stewart L., von Kriegstein K. \& Warren J. D. (2006) Music and the brain: disorders of musical listening. Brain, 129, 2533-2553.

Thaut M. H. (2005) The future of music in therapy and medicine. Annals of the New York Academy of Science, 1060, 303-308.

Tierney, A.T; Krizman, J.; Kraus, N (2015) music training alters the course of adolescent auditory developmente Proc Nat Acad Sci USA.Aug 11:112(32): 10062-10067.

Trimble M. R. (2007) The Soul in the Brain: The Cerebral Basis of Language, Art and Belief. Johns Hopkins University Press.

Trimble M. R. (2012) Why Humans Like to Cry. Tragedy, Evolution and the Brain. Oxford University Press. 
Trimble, M, Hesdorfer, D. (2017)Music and the brain: the neuroscience of music and musical appreciation BJPsych Int. 2017 May; 14(2): 28-31. 